\title{
دور الأسرة في الاختيار الزواجي للأبناء بحث ميداني في مدينة الديوانية
}

م . م رائد عبد السادة البديري

جامعة القادسيةـ كلية الاداب- قسم علم الاجتماع

\section{Raed.abdulsada@qu.edu.qu}

07816666167

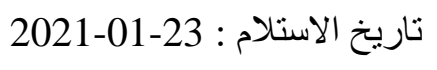

2021-3-28 : تاريخ القبول

ملخص البحث

نظراً للتغير ات الاجتماعية والاقتصادية الكبيرة التي يتعرض لها المجتمع والأفر اد كجزء منه، فقد ظهر أن هنالك تبدلاً على مستوى المعايير التي يفاضل على أساسها الأفراد في اختيار اتهم الزوجية، وتناقضها أحياناً مما تسبب في ظهور العديد من المشكلات الاجتماعية كارتفاع نسب المشكلات الزوجية وارتفاع نسب الطلاق وظهور الانحر افات وغير ها من المشكلات. لذا هدف البحث الى التعرف على آراء فئة من المقلين على الزواج عددها 245 نحو اختيار هم لشريك حياتهم في مدينة الديوانية لتكون المجتمع الخاص بالبحث، من خلال الكثف عن أهم وأول محاور نظام الاختيار الزواجي التي يعتمدها أو يفضلها في اختيار هم لثريك حياتهم وذلك لما يقدمه هذا النوع من البحوث من معرفة وفهم لطبيعة ميول الافراد نحو مختلف القضايا الحياتية. لللك يمكن تجسيد مشكلة البحث في بعض التساؤلات التي سيجيب عنها البحث و التي تتمثل في ما دور الأسرة في

الاختيار الزواجي؟ وما تأثثر الاختيار الزواجي على التوافق الأسري؟ وما الآثار الناجمة عن سوء الاختيار الزواجي؟

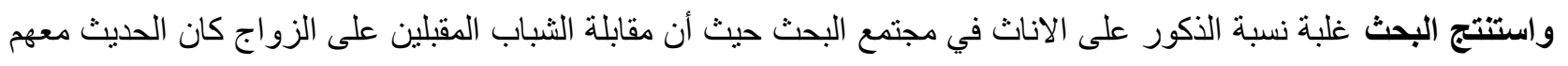
أسهل من الاناث المقلين على الزواج أيضاً، وأن الغالبية العظمى من عينة الدراسة تقع في الفئة العمرية من 25-35 أب الفئة الثبابية، واتضح ان توزيع افراد العينة حسب أي مرحله عمريه تفضل الزواج ففي الترتيب الاول من 20-25سنه بنسبه 46,9 وفي الترنيب الثاني من 25-30سنة بنسبة 40,8\% وفي النرتيب الثالث اقل من 20سنه بنسبه 12,2\% ، و وأن التسرع في الاختيار الزو اجي يؤدي الى مشاكل زوجية قد تؤدي الى الطلاق وهذا ما أكدته الغالبية العظمى من عينة الدراسة.

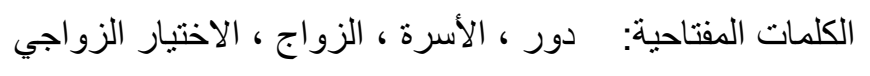


Assistant teacher Raed Abdul Sada Al-Badiri

Department of Sociology, College of Arts, Qadisiya University

Receipt date: 2021-01-23

Date of acceptance: 2021-03-28

\section{Abstract}

In view of the great social and economic changes that society and individuals are exposed to as part of it, it has emerged that there is a change in the standards on which individuals are preferred in their marital choices, and sometimes contradict them, which caused the emergence of many social problems, such as high rates of marital problems, high rates of divorce, the emergence of deviations, etc. Of the problems. Therefore, the research aimed to identify the opinions of a group of 245 intending to marry towards their choice of their life partner in the city of Diwaniyah to be the research community, by uncovering the most important and first axes of the marital selection system that they adopt or prefer in their choice of their life partner for what this type of Research on knowledge and understanding of the nature of individuals' tendencies towards various life issues. Therefore, the research problem can be embodied in some of the questions that the research will answer, which are: What is the role of the family in marital choice? What is the effect of marital choice on family compatibility? What are the effects resulting from poor marital choice?

The research concluded that the percentage of males is predominant over females in the research community, as meeting young men who are about to get married was easier to talk to than females who are about to get married as well, and that the vast majority of the study sample falls in the age group of 25-35, i.e. the youth group, and it became clear that the distribution of individuals The sample according to which age stage prefers marriage, in the first order from 20-25 years at a rate of $46.9 \%$, in the second order from $25-30$ years by $40.8 \%$, and in the third order, less than 20 years of age by $12.2 \%$, and that haste in marital selection leads to Marital problems that may lead to divorce, and this was confirmed by the vast majority of the study sample.

Opening words :family, role, Marriage ,Marital Choice

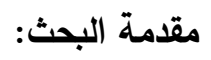


يعتبر الزواج نظاماً اجتماعياً حيوياً ومهماً في أي مجتمع إنساني؛ فهو صلة شرعية بين الجنسين يتم من خلال عقد يلتزم به الطرفان كسائر العقود، ويحافظ الإنسان به على بقاء النوع واستمرار الحياة، وقد شرع الله سبحانه وتعالى الزواج؛ لأن فيه المحبة والاستقرار والهحوء، وحفظاً للنسل، واستمرار بقاء الحياة، وحماية الأعراض والأنساب، وحفظ الإنسان من الأمراض النفسية والجسدية والأخلاقية. فالأسرة مؤسسة عظيمة ولبنة أولى في بناء المجتمع ويعتبر الزواج واحداً من أهم النظم الاجتماعية وأقدمها والذي من خلاله تتثكل النواة الرئيسية للدجمع الإنساني الأسرة كما يعد من الأحداث المهمة في حياة الفرد التي يدخل من خلالها مرحلة جديدة لها من الأدوار والأنماط ما يميزها عن المراحل السابقة، والزواج من أقدم النظم الاجتماعية وأكثرها شيوعاً وقبولاً، ولكي تتجح هذه المؤسسة في القيام بأدوارها المختلفة كان لابد من الاختيار السليم والموفق بين الزوجين حتى تقوم الأسرة على الحب والتألف والانسجام الذي ينعكس إيجابياً على أفرادها، ومن أهم القرارات التي يتخذها الإنسان في حياته قرار اختيار الزوجة لما له من دور أساسي في حياة الانسان لذا فإن الاختيار الزواجي السليم يعد أولى الخطوات التي تعمل على تحقيق التوافق الزواجي، وحتى يكون الاختيار سليم لابد ان يتوافر في الفرد الحرية والإرادة الكاملة والعقل الناضج إن للرجل الدور المباشر في عملية الاختيار الزواجي من خلال الاختيار الظاهري وإبداء الرغبة في الاختيار من خلال الخطبة، اما دور المرأة في عملية الاختيار الزواجي فيكون بطريقة غير مباشرة من خلال الموافقة على من يتقدم إليها أو رفضه،، واختيار شريك الحياة تتضمن إجراءات ترتبط بثقافة المجتمع وتتأثر بالمعايير الاجتماعية والرؤية الثخصية وتختلف أساليب الاختيار الزواجي بحسب ثقافة كل مجتمع، والاختيار يقوم بطريقتين هما: الزواج الحر (الاختياري) وفيه يكون الاختيار بطريقة فردية أي ان الثاب او الفتاة يقدمون على الزواج والاختيار دون تدخل من الوالدين أو الأقارب، أما الزواج المرتب: وفية يكون الاختيار من اختصاص الوالدين والأقارب والذي يتقرر في ضوء بعض الاعتبارات الاجتماعية والاقتصادية وقد يسح في بعض الحالات للفتاة أو الفتى بإبداء رأيهما، واختيار شريك الحياة يعتبر من الأمور المهمة التي يجابهها المرء في حياته والتي تتطلب درجة عالية من العقلانية والرشد والعمل الواعي الحكيم والاختيار الصحيح هو الطريق لحياة عائلية مستقرة ناجحة أي لابد من الاهتمام باختيار شريك الحياة والخضوع في اختياره لحكم سليم حتى يتسنى لهما تكوين الأسرة الناجحة. 
1- مشكلة البحث: يعد موضوع الزواج من الموضوعات المهمة التي يجب دراسته بإمعان، وتقصي الحقائق والمعلومات عنه وذلك لكونه النظام الاجتماعي الذي يقره المجتمع لتنظيم وضبط الحياة الجنسية لأفراده والذي في ضوئه تتحدد سلامة المجتمع وقوة تماسكه وخلوه من الكثير من المشكلات الاجتماعية والنفسية، بعدما يتحقق زواجاً ناجحاً ينعكس على المجتمع بدور إيجابي في تأسيس سليم لوحداته الاجتماعية وقدرتها على القيام بوظائفها بشكل صحيح من جهة أخرى، وبما توفره البيئة الأسرية بدورها من أمان واستقرار وتوافق نفسي يعود إيجاباً على الصحة النفسية للفرد من جهة أخرى.

ونظراً للتغيرات الاجتماعية والاقتصادية الكبيرة التي يتعرض لها المجتمع والأفراد كجزء منه، فقد لاحظنا شخصياً على أرض الميدان وكذلك من خلال اطلاعنا على العديد من الدراسات حول الموضوع، بأن هناك تبدلاً على مستوى المعايير التي يفاضل على أساسها الأفراد في اختياراتهم الزوجية، وتناقضها أحياناً مما تسبب في ظهور العديد من المشكلات النفسية كعدم التوافق الزواجي والإصابة بالأمراض النفسية بالإضافة إلى ظهور مشكلات اجتماعية كارتفاع نسب المشكلات الزوجية وارتفاع نسب الطلاق وظهور الانحرافات وغيرها من المشكلات.

وهذا ما دفعنا لدراسة الموضوع كمحاولة منا لتقديم فهم أعمق عن قضية ممثلة بتضضيلات الثباب الزواجية باعتبارها من العوامل الأولى لسلامة الأسرة والمجتمع إذا ما بني الزواج على اختيار متوافق وسليم. لذلك ارتائنا في بحثنا هذا التعرف على آراء فئة من المقبلين على الزواج عددها 245 نحو اختيارهم لشريك حياتهم في مدينة الديوانية لتكون المجتمع الخاص بالبحث، من خلال الكثف عن أهم وأول محاور نظام الاختيار الزواجي التي يعتمدها أو يفضلها الثباب المقبلين على الزواج في اختيارهم لشريك حياتهم وذلك لما يقدمه هذا النوع من البحوث من معرفة وفهم لطبيعة ميول الافراد نحو مختلف القضايا الحياتية. لذلك يمكن تجسيد مشكلة البحث في بعض التساؤلات التي سيجيب عنها البحث والتي تتمثل في:

$$
\text { 2- أ- ما دور الأسرة في الاختيار الزواجي؟ البحث: }
$$

ب- ما تأثير الاختيار الزواجي على التوافق الأسري؟ ج- ما الآثار الناجمة عن سوء الاختيار الزواجي؟ 3- أهداف البحث: أ- التعرف على دور الأسرة في الاختيار الزواجي. 
ب- التعرف على تأثير الاختيار الزواجي على التوافق الأسري. ج- التعرف على الآثار الناجمة عن سوء الاختيار الزواجي.

4- أهمية البحث: للبحث الحالي أهمية علمية تتمثل في أهمية موضوع البحث الذي يتتاول الاختيار الزواجي باعتباره الخطوة الأولى نحو بناء الأسرة التي تعد الوحدة الأساسية واللبنة الأولى للمجمع، هذا من جهة، ومن جهة أخرى فعندما ننظر إلى طبيعة المشاكل الأسرية أو المشاكل الزواجية وعدم التوافق ما بين الزوجين أو تفكك الأسرة من طلاق أو هجر وما يتبع هذا التفكك من ضحايا ومتضررين، لوجدنا أن معظم هذه الظواهر لها علاقة وجذور تمتد إلى خطوة أبعد حدود الموضوع نفسه، ولها علاقة بعملية اختيار شريك الحياة، فإذا حسُن الاختيار وقام على أسس متينة ومدروسة سلمت الأسرة، وبالتالي سلم المجتمع من مثل هذه الآفات التي باتت تهدد تماسك وصلابة الأسرة. كما للبحث أهمية عملية تتمثل في الكثف ميدانياً عن دور الأسرة في الاختيار الزواجي باعتبار أن المقبلين على الزواج هم أهم شريحة في المجتمع وهم يعيشون في ظل مجموعة من التغيرات الاجتماعية والثقافية والاقتصادية التي تمر بها المجمعات، في محاولة منا لفه واقع موضوع البحث وتقديم رؤية علمية تساعد في عملية الاختيار الزواجي وفي بناء أسرة متوافقة خالية من المشاكل النفسية والاجتماعية. 5

1-الدور: يعرف قاموس علم الاجتماع الدور بأنه نموذج تتركز حوله بعض الحقوق والواجبات ويرتبط بوضع محدد لمكانته داخل جماعة وموقف اجتماعي معين، ويحدد وضع الثخص في موقف عن طريق توقعات يعتنقها الآخرون كما يعتنقها الثخص أثناء علاقته بالآخرين داخل النسق الاجتماعي( بدوي، 1993 ). ويعرف الدور بأنه " المطالب المعينة بحكم تركيب الجماعة والمرتبطة بوضع اجتماعي معين"(ابراهيم، 2001 ). ويعـرف الـدور بأنـه "نمـاذج محددة ثقافيًا وملزمـة للفـرد الـني يحتـل مكانـه معينـة ومحددة ومعيـار اجتمـاعي معين على علاقة تبادلية معينة"(احمد، 2000 ).

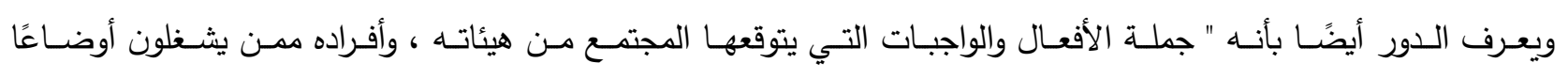
اجتماعية في مواقف معينة"(احمد، 1984 ). ومـن هذا المنطلق يمكن للباحث تحديد مفهوم الـدور في ضـوء البحث الحسالي إجرائيًا على أنـه: مجموعـة مـن الواجبـات و الأفعال والممارسات التي تقدمها الأسرة لأفرادها وتقديم الخدمات من خلال أدائها لدورها داخل الاسرة . 
2- الأسرة: يعرف أوجبرن الأسرة " أن الأسرة عبارة عن رابطة اجتماعية من زوج وزوجة وأطفالهما أو بدون أطفال أو من زوج بمفرده مع أطفاله أو من زوجة مع أطفالها ويضيف إلى أن الأسرة قد تكون أكبر من ذلك فتشمل أفراداً آخرين كالجذور A Handbook of Sociology, 1994) والأحفاد وبعض الأقارب على أن يكونوا مشتركين في معيشة واحدة مع الزوج والزوجة

والأسرة هي: "الوحدة الأولى للمجتم ومؤسساته التي تكون العلاقات فيها في الغالب مباشرة ويتم داخلها تتشئة الفرد اجتماعياً ويكتسب فيها الكثير من معارفه ومهاراته وميوله وعواطفه واتجاهاته في الحياة ويجد فيها أمنة وسكنه"( محمد عقلة،1989 17). تعريف بل وفوجل: الأسرة هي وحدة بنائية، تتكون من رجل وامرأة يرتبطان بطريقة منظمة اجتماعية مع أطفالهم ارتباطاً بيولوجياً أو بالتبني( غدنز، 2005 ).

تعريف بوجاردس: الأسرة هي جماعة اجتماعية صغيرة، تتكون عادة من الأب والأم وواحد أو أكثر من الأطفال، يتبادلون الحب ويتقاسمون المسئولية، وتقوم بتربية الأطفال حتى يمكنه من القيام بتوجيههم وضبطهم ليصبحوا أشخاص يتصرفون بطريقة اجتماعية(صالح، 2010 ). تعريف رينيه كوينج: الأسرة هي جماعة من نوع خاص، يرتبط أفرادها بعلاقة الشعور الواحد المترابط والتعاون والمساعدة المتبادلة، ويسهم أفراد واعين أصحاء في بنائها وتطويرها وإخراجها للمجتمع(عدلي، 2014 ). ويذهب نيمكوف في تعريفة للأسرة بأنها "رابطة اجتماعية من زوج وزوجة وأطفالهما أو دون أطفال، أو من زوج بمفردة مع أطفاله، أو من زوجة بمفردها مع أطفالها"(عصام، 1989 ). تعرف الأسرة بأنها جماعة من الأشخاص يرتبطون بروابط الزواج والدم أو التبني ويعيشون معيشة واحدة ويتفاعلون كل مع الآخر في حدود أدوار الزوج، الأم والأب، الأخ والأخت، ويشكلون ثقافة مشتركة(محم، 2006 ). التعريف الاجرائي: يمكن القول بأن الأسرة عبارة عن مؤسسة اجتماعية قائمة بذاتها وهي أساسية لبناء وتكوين أفراده، وتطبيع أعضائها بثقافة المجتمع ، وهي كمؤسسة تتصف بالاستمرار والدوام.

\section{3arriage الزواج}


يعرف من الناحية الاجتماعية بأنه وسيلة لاستمرار الحياة ودوامها في إنجاب الذرية وهو حجر الأساس والدعامة الكبرى التي يقوم عليها بناء الأسرة وخو رابطة مقدسة لما تقوم عليه من المعاني الإنسانية والعاطفية أكثر مما يقوم على أي معنى آخر( دعبس، 1995 ).

والزواج هو نظام يتصف بالاستمرار والامتثال للمعايير الاجتماعية، ويعيش الزوجان في حياة واحدة يقرها ويقبلها المجتمع) رشوان، 2003 ). يعرف بأنه المؤسسة الاجتماعية التي تمح لإثنين من البشر البالغين اللذين ينتميان إلى جنسين مختلفين (الذكر والأنثى) أن يعيشا معا ويكونا أسرة وأن يتتاسلا وأن ينجب ذرية يعترف بها المجتم؟ والزواج نظام لا يخص الفتى والفتاة اللذين سيرتبطان بعقد الزواج فقط ولكنه تداخل بين أسرتيهما أيضا، حيث تتشأ روابط المصاهرة بين الأسرتين(علاء، 2006 ). الزواج هو ميثاق تراض وترابط غايته الإحصان وإنشاء أسرة مستقرة تحت رعاية الزوجين فهو مؤسسة وشراكة بحقوق وواجبات وبناء للأجيال وتكوين المجتمع، فهو يتطلب الوعي الكافي والقدرة على تحمل المسؤولية والإصرار على النجاح (فيصل، 2012 انطلاقا من التعريفات السابقة نجد أن الزواج هو تلك العلاقة الرضائية التي تقوم بين الرجل والمرأة ينظمها القانون ويرضى عنها المجتمع وتقيد حل العشرة الطيبة والتعاون والمحافظة على الإنسان ويترتب عنها مجموعة من الحقوق والواجبات لكلا الزوجين.

\section{:Choice 4}

الاختيار مصطلح سوسيولوجي يثير إلى وضع فرد معين في جماعة أو مجتمع معين، ويعتمد الوضع على عدد من Ahmed Zaki Badaoui,1993(الات الاختيار الإيجابي أو السلبي التي يواجهها الفرد في إحدى الاختبارات السوسيوميترية والاختيار ينظر إليها كعملية تضيف والاحتفاظ بالأشخاص أو الأشياء وفق معايير محددة، كما أنه مرحلة تالية لمرحلة تحديد الأهداف ويتم الاختيار وفق لمعايير عديدة من بينها الأهمية الحداثة الوظيفة والممارسة(احمد، 1996 ). والاختيار ينظر إليها بوصفها عملية تصنيف والاحتفاظ بالأشخاص أو الأشياء وفق معايير محددة، إنه مرحلة تالية لمرحلة تحديد الأهداف ويتم الاختيار وفقاً لمعايير عديدة من بينها الأهمية الحداثة الوظيفية والممارسة. 
التعريف الإجرائي للاختيار: الاختيار هو عملية الانتقاء والتتضيل والاختيار من بين المعروض وفق معايير يحددها الفرد لنفسه أو بواسطة الآخرين أو قد يفرضها عليه المجتمع الذي يعيش فيه.

الاختيار الزواجي Marital Choice:

الاختيار الزواجي يعد الخطوة الأكثر أهمية لتكوين الأسرة إذ يعد نصف المعركة ومحدداً مهماً لسعادة الأسر، وهو الطريقة التي يغير بها الفرد وضعه من أعزب إلى متزوج، وهناك بعض الإجراءات المتفق عليها في جميع المجتمعات لابد من اتباعها لإتمام الزواج. إلا إن هذه الإجراءات تختلف من مجتمع إلى آخر وتشمل عناصر قانونية ودينية وطبقية وعمرية وغيرها ( الخولي، 1988 ). حيث إنه لابد من تحديد اللائقين أو الصاحين للزواج والذي بناءً عليه يجب على الفرد أن يختار زوجته في إطاره(عبدالخالق، 2011 ).

وعملية الاختيار خطوة مهمة في حياة الإنسان لأنه يقوم بنمط سلوكي يعبر عن رد فعل شخصية بكاملها لموقف برمتها الساعاتي، 2002 ). والاختيار الزواجي بدوره كعملية هو المرحلة الأولى المهيأة للمرتحل الأخرى التي تمر بها الأسرة خلال تثكلها وانبثاقها للوجود بوصفها شريحة رسمية من شرائح المجتمع المعترف بها( الضبع، 2008، ). كما تختلف المجتمعات في النظم التي تتبعها للاختيار الزواجي باختلاف ثقافة المجتمع فما يرضي به مجتمع بوصفه نظاماً للاختيار يرفضه مجتمع آخر إلا كل المجتمعات تتفق أن الاختيار في الزواج هو الخطوة الأولى والأساسية، فالاختيار للزواج سلوك اجتماعي يهدف إلى تحقيق نابغة من حاجة أساسية لاى الفرد.

وهو عملية نفسية إرادية تدخل في مسئوليات الفرد عن تتمية صحته النفسية فإن أحسن الاختيار كان خيرا له وإن أساء كان شرا عليه وفى ذلك توضيح لحكمة الاسلام فى إقامة الزواج الثرعي على إرادة الرجل والمرأة ورده لكل زواج فيه إكراه. التعريف الإجرائي للاختيار الزواجي: الاختيار الزواجي هي الطريقة أو الأسلوب الذي يختار به الفرد شريك حياته سواء بنفسه أو بمساعدة الآخرين وتغير وضعه الاجتماعي من أعزب إلى متزوج وذلك طبقًا لمعايير المجتمع الذي يعيش فيه. ثانياً: التوجه النظري للبحث 
النظرية البنائية والاختيار الزواجي والأسرة: تعتبر النظرية الوظيفية من أبرز الاتجاهات اهتماما بدراسة الأسرة. وذلك لأنها تهتم بدراسة كل التفاصيل التي تكثف عن الحياة اليومية للأسرة في محاولة فهم علاقة الأسرة كنسق اجتماعي بالأنساق الاجتماعية الأخرى في المجتمع من الناحيتين البنائية والوظيفية. كما أن الاهتمام بالفرد في الأسرة أصبح من العلامات المميزة لهذا الاتجاه عند عدد كبير من الذين يفضلونه كمدخل أساسي لفهم الأسرة الحديثة(محم، 1987 ). حيث تعد تحليلات الاتجاه البناء الوظيفي من أحدث التحليلات التي تتناول وظائف الزواج والأسرة، وأثاروا إلى أن البناء مجموعة من القواعد التي تحدد شكل الأسرة ومؤسسة الزواج كالأسرة النووية، الأسرة الأموية العائلة الممتدة وحدانية الزواج وتحقق الوظيفة كأي نظام اجتماعي ، أهدافا ظاهرة وضمنية وترتبط بأي وظيفة يؤديها النظام الاجتماعي ككل(السيد، 2006، ص27). فإن الاهتمام ينص على الأجزاء التي يتكون منها النسق الأسري في ارتباطها مع بعضها البعض عن طريق التقاعل والتساند مع الاهتمام بكل جزء وعنصر في النسق باعتباره مؤديا لوظيفة معينة في النسق الكلي أو قد يكون معوقًا لها وأن الاهتمام ينص على العمليات R. Hill \&Hanson, الداخلية في الأسرة والعلاقات التي تربط بين النسق الأسري والأنساق الخارجية الأخرى التي تحيط بها 1980 ). حيث يعتبر النسق الأسري من الأنساق الاجتماعية التي تؤثر وتتأثر بالأنساق الاجتماعية الأخرى وتعتبر الأنساق الاقتصادية والثقافية وغيرها من أبرز العوامل التي تؤثر في الزواج وبالتالي فإن الاختيار للزواج والنظام الاقتصادي تؤثر على الأسرة والفرد والتي تعتبر نسق أسري يتأثر بالأنساق المحيطة به أي علاقة تأثير وتأثر حيث تؤثر على الزواج وبالأخص عملية الاختيار الزواجي. حيث ينهض أصحاب البنائية الوظيفية على مسلمة في الزواج وهي أن الاختيار الزواجي هو نسق اجتماعي يتكون من شريكي الزواج وأسرة الشريكين والعلاقات الزواجية ويكون أسلوب اختيار الشريك مرتبط بالمكانة الاجتماعية والاقتصادية والقيمية والجسمية والجماعة القرابية ويعتمد عليهم كأسلوب أساسي في عملية الاختيار الزواجي لتكوين أسرة جديدة(محمد، 1984 ). حيث يعتمد الاختيار بين الشريكين على أساس السمعة والمكانة والوضع الطبقي والدخل وتعمل هذه العوامل الاجتماعية والاقتصادية دور هام في أنها ترشد أو توجه الفرد إلى الثريك المناسب فينظر الثريك إلى أهمية المعايير الاجتماعية والاقتصادية التي يحتلها المقبلين على الزواج وكذلك الأبوين والعائلتين في اختيار الثريكين في ضوء المكانة الاجتماعية والاقتصادية في عملية المفاضلة في اختيار شريك الحياة على خلفية طبقية وتعليمية وعرقية(علياء، 1988، ص128). فنظام الزواج كان أكثر جوانب الحياة الاجتماعية استجابة وتأثر بعوامل التغير الاجتماعي والاقتصادي والتكنولوجي 
وكان أكثر استجابة للتغيرات ليبدأ في الظهور نمطا جديدا أكثر تكيفًا بما له من خصائص بنائية وظيفية تتماشي ومستلزمات العصر ومتطلباته وأرجع العماء أسباب اختلاف أشكال الزواج وأنماط الأسرة إلى الظروف السائدة في المجتمع واتجه العلماء في تقسيراتهم وتحليلاتهم إلى النظرية الوظيفية وتعد الأسرة التي تتأسس كهدف من أهداف الزواج أحد تلك الأجزاء أو الأبنية المكونة للمجتمع ككل(فاتن، 2005 ).

بالتالي فإن الباحث سوف يعتمد على النظرية البنائية الوظيفية ويؤيدها لما لها من قيمة علمية وتساعد في دراسة موضوع البحث بتعمق واستفادة من خلال تتاول أنساق اجتماعية واقتصادية وثقافية وتأثيرها على عملية الاختيار الزواجي من قبل الثباب. ثالثاً: دور الأسرة في الاختيار الزواجي

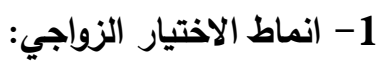

- العاطفي: وفيه يكون الاختيار قائمًا على عاطفة حب قوية، لا تخضع للعقل ولا للمنطق، ويعتقد صاحب هذا النمط بأن الحب وحده كافٍ لتخطي المشاكل وبناء حياة زوجية سعيدة، فبالتالي يصر على رأيه، ولا يستمع لنصائح الآخرين له، فيكون شديد العناد في الدفاع عن اختياره، ولا يوجد حل في هذه الحالة سوى تركه ليخوض التجربة بنفسه، وتحمل المسئولية لهذا الاختيار ونتائجه. - الاجتماعي: وهو زواج يقوم على التوافُق الاجتماعي المتعارَف عليه بين الناس. - العائلي: وهو زواج يُقصَد به لِّ شمل العائلة، أو اتباع تقاليد معينة؛ كالزواج من الأقارب. - الايني: وهو اختيار مبني على اعتبارات دينية، وهذا ما يؤيده الرسول صلى الله عليه وسلم والدين. - العشوائي: في هذه الحالة نجد الفتاة ترضى بأي زيجة؛ لأنها قد فاتها قطار الزواج فتخشى العنوسة. - العقلاني: وهو يقوم على حسابات منطقية لخصائص الطرف الآخر ، وبالتالي فهو يخلو من الجوانب العاطفية. - الجسدي: يقوم هذا النمط من الاختيار على الإعجاب بالمواصفات الثكلية للطرف الآخر، مثل جمال الوجه أو جمال الجسد. - المصلحي: وهو زواج يهدف تحقيق مصلحة مادية أو اجتماعية أو وظيفية من خلال الاقتران بالطرف الآخر . - المتكامل: وفيه يراعي الثخص عوامل متعددة لنجاح الزواج؛ كالعاطفي، والعقلي والجسدي، وهذا أفضل نمط للاختيار . 
- الهروبي: وفي هذا النمط نجد الفتاة مثلاً تقبل أي طارق لبابها؛ هروبًا من قسوة الأهل وسوء معاملتها، فلا تفكر في

$$
\text { الثخص المتقدم بقدر ما تفكر في الهرب من الواقع المؤلم الذي تعيشه(خلود، 2016، ص26). }
$$

2- أساليب الاختيار الزواجي: ويُقصَد به الأسلوب المفضل للاختيار في كل مجتمع، من حيث مدى تدخل أشخاص آخرين من غير الذين يعنيهم الأمر في عملية الزواج والترتيب له، وهناك أسلوبان:

أ- الاسلوب الوالدي في الاختيار: وهو الأسلوب الأكثر انتثارًا في المجتمعات العربية، حيث يتدخل الوالدان في عملية اختيار الثريك؛ سواء للابن أو للابنة، والذي يعد من وجهة نظرهم هو الأفضل، وإذا ما قام الثاب أو الفتاة بالاختيار، يكون للوالديْن حق الاعتراض، كما تقوم بعض الأُسر بعقد اتفاقيات زواج لأطفالهم الذين لم يبلغوا بعد سن الرشد، فتجد في هذا الأسلوب اعتاءً بالجوانب الاجتماعية والاقتصادية، وتهمل العاطفة والمشاعر التي يُفترَض أنْ تأتي بعد الزواج، فهو مشروع أسري وليس فرديًا، ويظهر هذا الأسلوب في الاختيار في المجتمعات القروية. ب- الاسلوب الذاتي او الثخصي: وهذا الأسلوب يعتمد على اختيار الشريك من قِتل الفتاة أو الثاب دون تدخل الأهل حيث يعد هذا الأسلوب الزواج مشروعًا شخصيًا، ويكون رأي الآباء استثاريًا فقط، وليس إلزاميًا، ويظهر هذا الثكل من الاختيار للزواج في البيئات الأعلى مستوى اجتماعيًا واقتصاديًا (دلال وآخرون، 2004 ). 3- آليات الاختيار : يمكن تقسيم آليات الاختيار إلى ثلاثة مستويات كالتالي: أ- الرؤية وإلتفكير: رؤية المتقدم للخطبة، والتحدث معه، والمحاولة بكل المهارات الحياتية استتتاج صفاته وطباعه وأخلاقه، وذلك من خلال الرسائل اللفظية وغير اللفظية الصادرة عنه. ب- الاستشارة: استثارة ذوي الخبرة والمعرفة بطباع البشر، وسؤال المقربين والمحيطين بالثخص المتقدم للزواج؛ وذلك لكي تُستوفى الجوانب التي لا يمكن الحكم عليها من مجرد المقابلة، ومعرفة التاريخ الطولي لشخصيته، وطبيعة أسرة المنشأ، وطبيعة المجتمع الذي عاش فيه. ج- الاستخارة: مهما بُخِل من جهذ في الرؤية والتنكير والاستشارة، تبقى جوانب مستترة في الشخص الآخر، لا يعلمها إلا الله الذي يحيط علمه بكل شيءٍ، ولا يخفى عليه شي؛ُ، ولهذا يتم اللجوء اليه؛ للوصول إلى القرار الصحيح، وخاصةً أن هذا القرار هو من أهم القرارات التي تتُخذ في حياتنا، إنْ لم يكن أهها على الإطلاق. والاستخارة هي استلهام الهدى والتوفيق من الله، بعد 
بذل الجهد البشري المكن، وتتم الاستخارة بصلاة ركتيني، يتبعها دعاء الاستخارة، ونتيجة الاستخارة تأتي في صورة توفيق وتوجيه في اتجاه ما هو خير، وتعطي للإنسان سندًا معنويًا هائلاً، وتحميه من الثعور بالندم بعد ذلك(محمد، 2007 ). إن العزم على الزواج واختيار شريك الحياة، هي الفترة الأكثر احتمالاً للاخول في صراع مع الوالدين، فهذه المرحلة تحدد العلاقة المستقبلية بين الأبناء والآباء. فالوالدين يعتقدان أن الأمثل لعائلة المصاهرة، هي الأساس في الإبقاء على الرابطة مع الابن أو البنت، كمصاهرة عائلة صديق أو من العائلة، في حين أن الأبناء يريدون من خلال اختيارهم الحر المحافظة على الرابطة الثانية فقط، هذان المبدأين يحددان قيام العلاقة المستقبلية بين الآباء والأبناء. لهذا فالنقص في الحوار وحواجز التواصل بين الوالدين وأبناؤهم، في هذا المجال من شأنه أن يؤدي إلى تأخير الزواج، أو الى الوقوع في صراع حول مسألة الاختيار بين الوالدين والأبناء خاصة إذا تم فرض شريك الحياة من طرف الوالدين أمام رغبة الثاب أو الثابة في الاختيار الحر. فهذه الوضعية في الحياة العائلية والمتعلقة باختيار شريك الحياة وقرار الزواج، يتم ضمن اندماج مزدوج بين ما هو تقليدي وحديث. تختلف عملية الاختيار الزواجي، من مجتمع لآخر وفق محددات الاختيار الزواجي ورغباته. فأما محدات الاختيار الزواجي وتتمثل في الزواج الداخلي ويقد به زواج الفرد من جماعته (القرابة)، والزواج الخارجي ويقصد به زواج من خارج الجماعة التي ينتسب إليها، الزواج الأحادي وهو النظام الذي لا يصح بمقتضاه، أن يكون للرجل أكثر من زوجة، واحدة في نفس الوقت. ثم الزواج التعدي هو ذلك النظام الزواج الذي يسح للشخص، بأن يتزوج أكثر من زوجة واحدة، في وقت واحد، وتشمل محددات الاختيار الزواجي، قيود كثيرة تفرض على الاختيار من قبل المجتمع مثل قيود السن، والمستوى الاقتصادي والاجتماعي. بينما تثمل رغبات الزواج كل الصفات والقيم التي يراها الفرد ذات أهمية في عملية الاختيار، كالجمال أو المال أو الأصل. فقد تسهم العديد من العوامل في تحديد ملامح بعض العلاقات الزوجية غير المتكافئة، وفي مقدمتها الظروف الاجتماعية التي تجبر الثباب أو الفتاة أحياناً على الارتباط بمن لا يرغب تبعاً لعادات. وتقاليد تجعل من الوالدين أو إحداهما طرفاً أساسياً في تحديد زوج أو زوجة المستقبل لأولادهم وتصل هذه العادات إلى مستوى القوانين الملزمة في بعض العائلات بحيث يتعين على الثاب الارتباط بأبنة عمه، والامر نفسه تواجهه الفتاة التي يتعين عليها في كثير من الحالات أن ترتبط في من لم تفكر أن تفكر أن يكون شريك حياتها يوماً، غير أنها تخضع للأعراف المجتمعية التي تختار لها عريسها، فيما يتناسى 
الأهل في مثل هذه الحالة أن مؤسسة الزواج المبنية على التفاهم. والاقتتاع أولاً، وثم الحب يتعين على طرفيها (الزوج والزوجة) تحديد أساسياتها.

يعتبر قرار الاختيار أحدهم أهم القرارات التي يتخذها الإنسان في حياته، إذ أن نجاح الحياة الأسرية يتوقف على اختيار شريك الحياة المناسب؛ لأنه أساس عملية الزواج، فنجاح الاختيار يترتب عليه نجاح الزواج وبالتالي تحقق السعادة للفرد، وكثيراً من حالات فثل الزواج يعود إلى الاختيار غير السليم للشريك مما يسبب عدم توافق بين الثريكين في التوجهات والآراء، وقد يكون سوء الاختيار مرتبطاً بالاختلاف في جوانب متعددة مثل: اختلاف المركز أو المكانة الاجتماعية والاقتصادية أو التعليم أو الدين بما ينعكس سلباً على التفاعل بين الطرفين والأسرة ككل. والاختيار في الزواج هو الخطوة الأولى لبناء الأسرة التي تعد حجر الأساس في المجتمع وتحظي بالكثير من الاهتمام للعناية والزواج عبارة عن نظام مؤسسي، وسبب في استقرار الرجل والمرأة نفسياً واجتماعياً وعاطفياً، وهو يشبع ميول الإنسان في تكوين أسرة كما يشبع غرائزه حقاً لكل إنسان، ويترتب عليه حقوق وواجبات وبه تتشأ علاقة بين الزوجين مبنية على المودة والرحمة.

لكن بسبب التغيرات العلمية والاقتصادية، التي عرفها العالم والتي أثرت بدورها على المجتمع العراقي بصفة عامة، وعلى الأسرة بشكل خاص، حيث زاد الاهتمام بتعليم المرأة وخروجهما للعمل مما غير في الأدوار الأسرية. وظهور معايير اجتماعية جديدة، كلها هذا كان له تأثير على الثباب، وأصبح لديه تصور خاص به في شتى المواضيع بما في ذلك موضوع الاختيار الزواجي. رابعاً: الآثار المترتبة على سوء الاختيار الزواجي لا شك أن اول الأسس المطلوبة لبناء أسرة سعيدة هو أن يكون الزواج بناء على الرغبة المتبادلة والاختيار المطلق والرضا الكامل حتى يمكن أن تكون هناك حياة مستقرة يأنس كل طرف فيها الى شريك حياته ورفيق عمر، وإذا كان الرجل يتمتع الى حد كبير بحرية اختيار شريكة حياته فإن المرأة كانت وما تزال في بعض المناطق تحرم من هذا الحق فهي واقعة تحت رحمة أبيها أو ولي أمرها في أهم قضية تخص حياتها ومستقبلها(زايد، 2006 )، أن الظروف النفسية المصاحبة للزواج تؤثر كثيراً في العلاقات داخل الأسرة مثل ضغوط الأهل لقبول شخص معين ضد رغبة الفرد، فأحياناً قد يفرض الأهل شخصاً معينا على ابنتهم يرونه مناسبا من وجهة نظرهم، ونحن لا ننكر ما لوجهة نظر الاهل من اهمية في الاختيار شريك الحياة ولكن في الوقت نفسة يجب ألا تتعارض وجهة نظرهم مع وجهة نظر الابنة فهي التي سوف تعيش مع هذا الشخص فلابد أن تتقبله نفسياً فإذا شعرت 
الابنة بالنفور منه فإنه من الخطأ الجسيم أن نجبرها على الزواج منه مهما كان لديه من مميزات كالوظيفة المرموقة أو السكن الملائم أو ما إلى ذلك من ضمانات مادية ونفس الثيء يقال في حالة محاولة الأهل فرض شخص معين مثل القرببات على الأبن الذي يشعر ناحيتها إلا بشعور الأخوة(سميحة، 1996، ص42)، وأيضاً الاختيار لغاية لم تتحقق فمنهم من يكون هدفه الاستقرار وتحقيق الأمان النفسي وإنثاء الأسرة الصالحة والبعض يهدف الى تحقيق غايات مادية أو معنوية كأن يتزوج امرأة يرجو من ورائها الحصول على المال كأن تكون موظفة أو من أسرة ثرية وكذلك من يتزوج امرأة بنت ذي جاه أو سلطان فإذا لم يتحقق له ما تصبو إليه نفسه انقلبت حياته رأساً على عقب ودبت الخلافات بينه وبين زوجته. والأسرة هي المسؤولة عن تقشى ظاهرة الطلاق السريع بعد الزواج ..ذلك أن البنت أحياناً لا تجد الإثباع العاطفي الكافي من الأب والأم وبالتالي تبحث عن هذه العواطف خارج البيت، وتتسارع الى الزواج لعل وعسى أن يعوضها عن هذا النقص وأحياناً يكون تكوين الأسرة غير سليم ويريد الأب والأم فيها سرعة زواج البنت إما لتخفيف المسئولية عن الأسرة أو اعتقاد بأن زواج البنت سترة وبالتالي يتم الزواج في سن مبكرة دون ان تفهم البنت التعاليم والأهداف الصحيحة السليمة للزواج(سناء، 2008، ). وقد يتسبب الإسراع في الزواج دون تمهل وروية في خلق كثير من المشكلات التي تواجه الزوجين حيث يجهل كل منهما الكثير من خصائص وطبائع الآخر فيما يتعلق بأي مجال من مجالاته الثخصية والاجتماعية والتربوية والمهنية والتي قد يكتثفها بعد الزواج ويشعر بأنها لا تعجبه فيه فيحاول تغييرها أو تبديلها ولكنه لا يقدر على ذلك فيصطدمان مع بعضهما بما لا يدع مجالا للصبر ولا للتسامح من جانب أي منهما وهو ما يجعلهما يسيران في طريقين متضادين حيث يبعدان عن بعضهما بلا رجعة فيحدث الطلاق بينهما (سميحة، 1996، ص74). يثهد المجتمع العراقي العديد من المشكلات الاجتماعية والاقتصادية والثقافية التي تمارس تأثيراً على الفرد المقبل على الزواج بل تؤثر تأثير واضحاً في قرار الاختيار الزواجي، وذلك لأن عملية الاختيار الزواجي تتأثر الى حد كبير بالأبعاد الاجتماعية والاقتصادية والثقافية التي يعيش فيها الافراد المقبلين على الزواج أن الاختيار الزواجي على صلة وثيقة بما يطرأ على المجتمع من تغيرات، وتدخل الاسرة في الاختيار للزواج سواء كانت اسرة ممتدة يكون القرار لكبار السن في الأسرة هم من يقومون بالاختيار للأحفاد ويكون الاختيار مراعاةً لمصلحته الاقتصادية ومصلحة الاسرة دون أخذ رأي الابن بالموافقة أو الرفض. خامساً: الإجراءات المنهجية للبحث الميداني 
مجلة لارك لدذلسفة واللسدانيات و العلوم الاجتماعية المجلد (2) العدد (41) السدة (2021) بحوث علم الاجتماع وعلم الذفس

1 - نوع البحث: يُعد البحث الراهن من الدراسات الوصفية التحليلية Descriptive Study.

2- منهج البحث: اعتمد البحث الراهن على منهج المسح الاجتماعي تمشيا مع البحث الحالي وأهدافه تم استخدام منهج المسح

الاجتماعي بالعينة.

3- أدوات البحث: اعتمد الباحث في هذا البحث على أداة رئيسية وهي استمارة الاستبيان.

4- مجتمع البحث وعينة الاراسة: من أجل اثبات تساؤلات البحث جرى اختيار مدينة الديوانية لتكون المجتمع الخاص بالبحث، واختار الباحث عينة من المقبلين على الزواج عددها 245 على أساس السن والحالة الاجتماعية والعمل في محكمة الاحوال الثخصية.

$$
\text { 5- مجالات البحث: يمكن توضيحها على النحو الآتي: }
$$

أ- المجال الجغرافي: حدد الباحث مدينة الديوانية مجالاً جغرافياً للبحث.

ب- المجال البثري: اختار الباحث عينة من المقبلين على الزواج عددها 245 على أساس السن والحالة الاجتماعية والعمل في محكمة الاحوال الثخصية في مدينة الديوانية. ج- المجال الزمني: استغرق البحث الميداني ما يقرب من 3 أشهر عن كل مرحلة من المراحل الثلاث المكتبية والتطبيقية وكتابة التقرير النهائي للبحث الراهن.

وفيما يلي نتتاول تحليل النتائج الميدانية الخاصة بالبحث الراهن، وسوف يتم تتاول كل هذه النقاط بالتنصيل كما يلي: أولاً : البيانات الأولية جدول رقم (1) توزيع أفراد العينة حسب التركيب النوعي للمبحوثين

\begin{tabular}{|c|c|c|}
\hline$\%$ & التركيب النوعي \\
\hline 55,1 & 135 & أنثى \\
\hline 44,9 & 110 & المجموع \\
\hline 100 & 245 & \\
\hline
\end{tabular}


مجلة لاررك للفلسدفة واللسدانيات و العلوم الاجتماعية المجلد (2) العدد (41) السذة (2021) بحوث علم الاجتماع وعلم الذفس

يوضح الجدول السابق توزيع أفراد العينة حسب التركيب النوعي للمبحوثين ففي الترتيب الأول الذكور بنسبة 55,1\% والإناث في الترتيب الثاني بنسبة 44,9\%. نستتتج مما سبق غلبة نسبة الذكور على الاناث في مجتمع البحث حيث أن مقابلة الثباب المقبلين على الزواج كان الحديث معهم أسهل من الاناث المقبلين على الزواج أيضاً. جدول رقم (2) توزيع أفراد العينة حسب عمر المبحوثين

\begin{tabular}{|c|c|c|}
\hline$\%$ & العدد & العمر \\
\hline 26,5 & 65 & أقل من 25 \\
\hline 51,0 & 125 & $35-25$ \\
\hline 22,4 & 55 & $45-35$ \\
\hline 100 & 245 & المجموع \\
\hline
\end{tabular}

يوضح الجدول السابق توزيع أفراد العينة حسب عمر المبحوثين ففي الترتيب الأول من 25- 35 وفي الترتيب الثاني أقل من 25 بنسبة 26,5\% وفي الترتيب الثالث من 35-45 بنسبة 22,4\%. مما سبق نستتتج أن الغالبية العظمى من عينة الدراسة تقع في الفئة العمرية من 25-35 أي الفئة الثبابية اللذين هم قادة وبناة المستقبل الذي يعتمد عليهم في بناء الاسرة والمجتمع والتي لابد أن يكون اختيارهم الزواجي مبني على أسس ذات قواعد سليمة لكي يكونوا أسر نافعة وتفيد في تقدم المجتمع • جدول رقم (3) توزيع أفراد العينة حسب الحالة التعليمية للمبحوثين

\begin{tabular}{|c|c|c|}
\hline$\%$ & العدد & الحالة التعليمية \\
\hline 8,2 & 20 & أمي \\
\hline 6,1 & 15 & يقرأ ويكتب \\
\hline 11,0 & 27 & متوسطة \\
\hline 29,8 & 73 & اعدادية \\
\hline 38,8 & 95 & معهد \\
\hline
\end{tabular}


مجلة لارك لذفلسدفة والذساذيات و الـعلوم الاجتماعية المجلد (2) العدد (41) السذة (2021) بحوث علم الاجتماع وعلم الذفس

\begin{tabular}{|c|c|c|}
\cline { 2 - 3 } & 15 & \\
\hline 100 & 245 & المجمويوس \\
\hline
\end{tabular}

يوضح الجدول السابق حسب الحالة التعليمة للمبحوثين ففي الترتيب الأول معهد بنسبة 38,8\% وفي الترتيب الثاني اعدادية بنسبة 29,8\% وفي الترتيب الثالث متوسطة بنسبة 11,0\% وفي الترتيب الرابع أمي بنسبة 8,2\% وفي الترتيب الخامس يتساوى يقرأ ويكتب وبكالوريوس بنسبة 6,1\%. من السابق يتضح اختلاف المستوى التعليمي للمبحوثين ففي المقدمة معهد مما يدل ذلك على قدرة عينة الدراسة على الاختيار الصحيح الذي يساعد على بناء أسرة جديدة ذات مبادئ وأسس. جدول رقم (4) توزيع أفراد العينة حسب مهنة المبحوثين

\begin{tabular}{|c|c|c|}
\hline$\%$ & العدد & مهنة المبحوثيين \\
\hline 27,3 & 67 & موظف حكومي \\
\hline 17,6 & 43 & كاسب \\
\hline 24,1 & 59 & أعمال حرة \\
\hline 14,3 & 35 & طالب \\
\hline 16,7 & 41 & بدون عمل \\
\hline 100 & 245 & المجموع \\
\hline
\end{tabular}

يوضتح الجدول السابق توزيع أفراد العينة حسب مهنة المبحوثين ففي الترتيب الأول موظف حكومي بنسبة 27,3\% وفي الترتيب الثاني اعمال حرة بنسبة 24,1\% وفي الترتيب الثالث كاسب بنسبة 17,6\% وفي الترتيب الرابع بدون عمل بنسبة 16,7\% وفي الترتيب الخامس طالب بنسبة 14,3\%.

يتضح من السابق اختلاف مهن الغالبية العظمى من عينة الدراسة فمنهم الموظف الحكومي وكاسب والأعمال الحرة ومن بدون عمل واخيراً الطلاب. ثانياً: طرق الاختيار الزواجي وأسبابه: 
مجلة لارد لدفلسدة و اللسدانيات و العلوم الاجتماعية المجلد (2) العدد (41) السدنة (2021) بحوث علم الاجتماع وعلم الذفس جدول رقم (5) توزيع أفراد العينة حسب في أي مرحلة عمرية تفضل الزواج

\begin{tabular}{|c|c|c|}
\hline$\%$ & العدد & المرحلة العمرية \\
\hline 12,2 & 30 & أقل من 20 سنة \\
\hline 46,9 & 115 & من 20-25سنة \\
\hline 40,8 & 100 & من 25-30سنة \\
\hline 100 & 245 & المجموع \\
\hline
\end{tabular}

يوضح الجدول السابق توزيع افراد العينة حسب أي مرحله عمريه تفضل الزواج ففي الترتيب الاول من 20-25سنه بنسبه

46,9 وفي الترتيب الثاني من 25-30سنة بنسبة 40,8\% وفي الترتيب الثالث اقل من 20سنه بنسبه 12,2\% .

تعتبر الأسرة الركيزة الأساسية لبناء المجتمع السليم، حيث إنه لا تعايش إنساني وحياة إنسانية بلا أسرة، وبشكل عام لا توجد هناك قاعدة ثابتة تُطبق على الذكور والإناث ليتم بموجبها تحديد السن والزمن الأفضل لاخولهم في الحياة الزوجية والأسرية، حيث إن هناك العديد من الجوانب التي يتوقف عليها مدى أهلية الرجل أو المرأة للزواج كتحقيق مستوى الوعي والنضج المطلوب، وإمكانية التعامل الإيجابي مع التغيرات الجذرية التي تتبع الانتقال إلى الحياة الزوجية، بالإضافة إلى طموحات الأفراد في تحقيق المستوى والتحصيل العلمي المطلوب، كما تختلف مُحددات السن المناسب للزواج باختلاف أنماط الحياة والبيئات والمجتمعات التي يعيش بها الأفراد.

جدول رقم (6) توزيع أفراد العينة حسب كيفية اختيار شريك الحياة

\begin{tabular}{|c|c|c|}
\hline$\%$ & 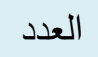 & 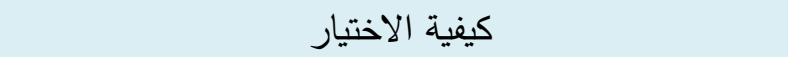 \\
\hline 59,2 & 145 & على أساس الحب للطرف الآخر (الاختيار العاطفي الحر) \\
\hline 40,8 & 100 & مبني على اختيار الأهل (الاختيار العائلي/ الزواج التقليدي) \\
\hline 100 & 245 & 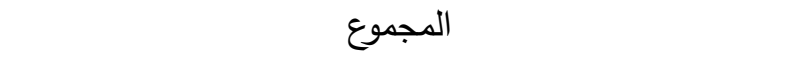 \\
\hline
\end{tabular}


يوضتح الجدول السابق توزيع افراد العينة حسب كيفيه اختيار شريك الحياه ففي الترتيب الاول على اساس الحب للطرف الاخر (الاختيار العاطفي الحر) بنسبه 59,2\% وفي الترتيب الثاني مبني على اختيار الاهل (الاختيار العائلي- الزواج التقليدي) بنسبه 40,8 \% .

نستتتج مما سبق بين مؤيد ومعارض لفكرة الزواج التقليدي والزواج عن حب وأيهما أنجح من حيث الاستقرار والاستمرار ، أن الزواج التقليدي من الممكن ان يكون محكوم عليه بالفشل وعدم الاستمرار لعدم معرفة الشريكين لبعضهما مسبقا، في حين أن الحب يكلل العلاقة الزوجية بالنجاح، لأن الارتباط العاطفي معناه اتفاق الشريكين على كل شيء في الحياة، مما يشعرهما بالأمان والاستقرار وتقاسمهما الحياة سويا. جدول رقم (7) توزيع أفراد العينة حسب تفضيل أسلوب التعامل من الطرف الآخر

\begin{tabular}{|c|c|c|}
\hline$\%$ & العدد العد & أسلوب التعامل \\
\hline 57,1 & 140 & أسلوب المودة والرحمة \\
\hline 8,2 & 20 & أسلوب النبذ والإهمال \\
\hline 28,6 & 70 & أسلوب التدليل \\
\hline 6,1 & 15 & أسلوب التسلط والقوة \\
\hline 100 & 245 & المجموع \\
\hline
\end{tabular}

يوضح الجدول السابق توزيع أفراد العينة حسب تفضيل أسلوب التعامل من الطرف الآخر ففي الترتيب الأول أسلوب المودة والرحمة بنسبة 57,1\% وفي الترتيب الثاني أسلوب التدليل بنسبة 28,6\% وفي الترتيب الثالث أسلوب النبذ والإهمال بنسبة

$$
\text { 8,2 8,2 وفي الترتيب الرابع أسلوب التسلط والقوة بنسبة 6,1\%. }
$$

نستتج مما سبق تعدد أساليب التعامل مع الآخر من وجهة نظر عينة الدراسة فالغالبية العظمى من المبحوثين ترى أن أسلوب المودة والرحمة هو أفضل أساليب التعامل بين الزوجين يليها أسلوب التدليل ثم النبذ والإهمال واخيرا التسلط والقوة. جدول رقم (8) توزيع أفراد العينة حسب دور الأسرة في اختيار شريك الحياة
$\%$
العدد
دور الأسرة 
مجلة لارك لذفلسدفة والذساذيات و الـعلوم الاجتماعية المجلد (2) العدد (41) السذة (2021) بحوث علم الاجتماع وعلم الذفس

\begin{tabular}{|c|c|c|}
\hline 59,2 & 145 & دور كبير \\
\hline 32,7 & 80 & دور محدود \\
\hline 8,2 & 20 & ليس لها دور \\
\hline 100 & 245 & المجموع \\
\hline
\end{tabular}

يوضح الجدول السابق توزيع افراد العينة حسب دور الأسرة في اختيار فن شريك الحياه ففي الترتيب الاول دور كبير بنسبه

59,2 وفي الترتيب الثاني دور محدود بنسبه 32,7\% وفي الترتيب الثالث ليس لها دور بنسبه 8,2\% .

يؤمن كثيرون بأن رأي الوالدين هو المرجعية المسلم بها، وفي مثال على ذلك نرى الثاب الذي يوكل امر زواجه لوالدته، والتي تقوم بدورها بالبحث والسؤال عن العروس المناسبة له او العريس المناسب للفتاة تبعاً لمقاييسها الخاصة، بينما ترفض فئة اخرى من الثباب من كلا الجنسين تسليم اختيار توأم الروح المفترض الى اي شخص آخر سواء اكان احد الوالدين او أي شخص غيرهما. جدول رقم (9) توزيع أفراد العينة حسب تفضيل اختيار الطرف الآخر

\begin{tabular}{|c|c|c|}
\hline$\%$ & 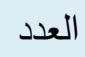 & تفضيل الاختيار \\
\hline 26.5 & 65 & الحب قبل الزواج \\
\hline 20,4 & 50 & الحب بعد الزواج \\
\hline 38,8 & 95 & الحب قبل وبعد الزواج \\
\hline 14,3 & 35 & بدون حب \\
\hline 100 & 245 & المجموع \\
\hline
\end{tabular}

يوضح الجدول السابق توزيع افراد العينة حسب تفضيل اختيار الطرف الاخر ففي الترتيب الاول الحب قبل وبعد الزواج بنسبه 38,8\% وفي الترتيب الثاني الحب قبل الزواج بنسبه 26,5\% وفي الترتيب الثالث الحب بعد الزواج بنسبه 20,4\% وفي الترتيب الرابع بدون حب بنسبه 14,3\% . نستنتج مما سبق أن الغالبية العظمى من عينة الدراسة تفضل الحب قبل وبعد الزواج يليه الحب قبل الزواج ثم الحب بعد الزواج واخيراً بدون حب. 
مجلة لارد لدفلسدة و اللسدانيات و العلوم الاجتماعية المجلد (2) العدد (41) السدنة (2021) بحوث علم الاجتماع وعلم الذفس جدول رقم (10) توزيع أفراد العينة حسب العوامل التي تؤثر على الاختيار الزواجي

\begin{tabular}{|c|c|c|}
\hline$\%$ & 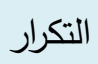 & العوامل المؤثرة في الاختيار الزواجي \\
\hline 14,3 & 35 & الوضع الاجتماعي \\
\hline 19,2 & 47 & المحيط العائلي \\
\hline 10,2 & 25 & درجة القرابة \\
\hline 11,4 & 28 & الشكل الخارجي \\
\hline 20,4 & 50 & الاهتمامات المشتركة \\
\hline 24,5 & 60 & المكانة الاجتماعية \\
\hline 100 & 245 & المجموع \\
\hline
\end{tabular}

يوضح الجدول السابق توزيع افراد العينة حسب العوامل التي تئثر على الاختيار الزوجي ففي الترتيب الاول المكانة الاجتماعية بنسبه 24,5\% وفي الترتيب الثاني الاهتمامات المشتركة بنسبه 20,4 \% وفي الترتيب الثالث المحيط العائلي بنسبه 19,2 \% وفي الترتيب الرابع الوضع الاجتماعي بنسبه 14,3\% وفي الترتيب الخامس الثكل الخارجي بنسبه 11,4\% وفي الترتيب السادس درجه القرابة 10,2\%. عند التثكير بكيفية اختيار شريك الحياة المناسب، الأخذ بعين الاعتبار تساوي القدرات والذكاء بين الثريكين، ولذلك ينصح باختيار الثريك الذي يقدر قيم وأهداف الطرف الآخر ، والقدرة على مشاركة القيم للوصول لهدف مشترك وطريق واحد، كما وينصح عند اختيار شريك الحياة أن تتوافق الخلفيات الاجتماعية لدى الفردين، والبحث عن الثخص الذي يتمتع بالصبر والفهر والدعم الذاتي والمعنوي، خاصةً للأحلام والأمنيات فلابد وضع المكانة الاجتماعية والطبقة والاهتمامات المشتركة والمحيط العائلي والوضع الاجتماعي والثكل الخارجي وأخيراً درجة القرابة. جدول رقم (11) توزيع أفراد العينة حسب تأييد فكرة اختيار شريك الحياة عن طريق الوسائل الحديثة مثل الإنترنت

\begin{tabular}{|c|c|c|}
\hline$\%$ & تأييد الفكرة \\
\hline 20,4 & 50 & العدد \\
\hline
\end{tabular}


مجلة لارك لذفلسدفة والذساذيات و الـعلوم الاجتماعية المجلد (2) العدد (41) السذة (2021) بحوث علم الاجتماع وعلم الذفس

\begin{tabular}{|c|c|c|}
\hline 18,4 & 45 & لالى \\
\hline 61,2 & 150 & لا مالمجع \\
\hline 100 & 245 & المجمع \\
\hline
\end{tabular}

يوضح الجدول السابق توزيع افراد العينة حسب تأييد فكره اختيار شريك الحياه عن طريق الوسائل الحديثة مثل الانترنت ففي

الترتيب الاول لا بنسبه 61,2\% وفي الترتيب الثاني نعم بنسبه 20,4 \% وفي الترتيب الثالث الى حد ما بنسبه 18,4\% . نستنتج مما سبق أن الغالبية العظمى من عينة الدراسة لا تؤيد فكرة الزواج عن طريق الوسائل الحديثة يليها من يوافق بذلك ثم

من يوافق الى حد ما.

جدول رقم (12) توزيع أفراد العينة حسب التسرع في الاختيار الزواجي يؤدي الى مشاكل زوجية قد تؤدي الى الطلاق

\begin{tabular}{|c|c|c|}
\hline$\%$ & التكرار & التسرع في الاختيار \\
\hline 79,6 & 195 & نعم \\
\hline 20,4 & 50 & $y$ \\
\hline 100 & 245 & المجموع \\
\hline
\end{tabular}

يوضح الجدول السابق توزيع أفراد العينة حسب التسرع في الاختيار الزواجي يؤدي الى مشاكل زوجية قد تؤدي الى الطلاق

$$
\text { ففي الترتيب الأول نعم بنسبة 79,6\% وفي الترتيب الثاني لا بنسبة 20,4\%. }
$$

يتضح مما سبق أن التسرع في الاختيار الزواجي يؤدي الى مشاكل زوجية قد تؤدي الى الطلاق وهذا ما أكدته الغالبية

العظمى من عينة الدراسة.

جدول رقم (13)توزيع أفراد العينة حسب أبرز المشكلات التي قد يعاني منها الزوجين نتيجة سوء الاختيار الزواجي

\begin{tabular}{|c|c|c|}
\hline$\%$ & التكرار & المشكلات التي قد يعاني منها الزوجين نتيجة سوء الاختيار الزواجي \\
\hline 10,2 & 25 & التباين في المستوى الاجتماعي والثقافي بين الزوجين ونثأة الصراع بينهما \\
\hline 16,3 & 40 & الفشل في العلاقات الجنسية بين الطرفين \\
\hline 14,3 & 35 & تباين الصفات المزاجية وردود الفعل الانفعالية \\
\hline
\end{tabular}


مجلة لارك لذفلسدفة والذساذيات و الـعلوم الاجتماعية المجلد (2) العدد (41) السذة (2021) بحوث علم الاجتماع وعلم الذفس

\begin{tabular}{|c|c|c|}
\hline 22,4 & 55 & استقلال المرأة الاقتصادي وعدم فهم دورها في بناء الأسرة السعيدة \\
\hline 24,5 & 60 & كثرة ترديد كلمة الطلاق \\
\hline 12,2 & 30 & تخخل الأهل في خصوصيات الزوجية \\
\hline 100 & 245 & المجموع \\
\hline
\end{tabular}

يوضح الجدول السابق توزيع أفراد العينة حسب أبرز المشكلات التي قد يعاني منها الزوجين نتيجة سوء الاختيار الزواجي ففي الترتيب الأول كثرة ترديد كلمة الطلاق بنسبة 24,5\% وفي الترتيب الثاني استقلال المرأة الاقتصادي وعدم فهم دورها في بناء الأسرة السعيدة بنسبة 22,4\% وفي الترتيب الثالث الفشل في العلاقات الجنسية بين الطرفين بنسبة 16,3\% وفي الترتيب الرابع تباين الصفات المزاجية وردود الفعل الانفعالية بنسبة 14,3\% وفي الترتيب الخامس تدخل الأهل في خصوصيات الزوجية بنسبة 12,2\% وفي الترتيب السادس التباين في المستوى الاجتماعي والثقافي بين الزوجين ونشأة الصراع بينهما بنسبة 10,2\%. نستتج مما سبق أن للطلاق أسبابه المتعددة، فمنها المفهوم الذي يمكن حصره ومناقثته، ومنها الذي يتسم بالهوجائية المتسرعة وهو الذي لا يمكن مناقثته إلا تحت عنوان عدم معرفة قيمة الزواج أو الاستهتار وعدم تحمل مسئولية القرار في إنشائه أو إنهائه، ولكن أبرز الأسباب وأكثرها وجودا أن يكون الطلاق ناتجا عن سوء اختيار من كلا الزوجين أو من أحدهما، وذلك في الوقت الذي ينعدم فيه وجود دور تربوي حقيقي ومؤثر وحكيم للأسرة والأهل في اتخاذ هذا القرار أو ذاك، وهناك ارتباط وثيق بين هاتين المرحلتين وبين قضية سوء الاختيار ، فيجمع بينهما التعجل في اختيار الزوجين نتيجة عدة عوامل وضغوط وهمية. جدول رقم (14) توزيع أفراد العينة حسب التصرف عند اعتراض الأهل على اختيار الثريك لأنه غير مناسب

\begin{tabular}{|c|c|c|}
\hline$\%$ & 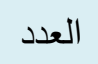 & التصرف عند اعتراض الأهل \\
\hline 81,6 & 200 & اتغاضى عن كلام الأصدقاء والقرار قراري وحدي وأنا الذي سوف يعيش معه \\
\hline 6,1 & 15 & اتغاضى عن كلام الأهل لأنها حياتي ومستقبلي \\
\hline 12,2 & 30 & استمع لكلام الأهل حتى لا أندم فيما بعد \\
\hline 100 & 245 & 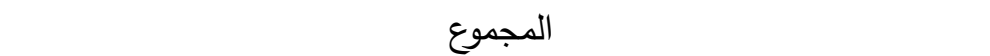 \\
\hline
\end{tabular}


يوضح الجدول السابق توزيع افراد العينة حسب التصرف عند اعتراض الاهل على اختيار الثريك لأنه غير مناسب ففي الترتيب الاول أتغاضى عن كلام الاصدقاء والقرار قراري وحدي وانا الذي سوف يعيش معه بنسبه 81,6\% وفي الترتيب الثاني استمع لكلام الاهل حتى لا اندم فيما بعد بنسبه 12,2\% وفي الترتيب الثالث أتغاضى عن كلام الاهل لأنها حياتي ومستقبلي بنسبه \%,1 نستتتج مما سبق أن الغالبية العظمى من عينة الدراسة تتغاضى عن كلام الأصدقاء والقرار قرارهم وحدهم لأنهم هم اللذين يعيشون مع الشريك لوحدهم يلي ذلك من يستمع الى كلام الأهل حتى لا يندموا فيما بعد ويليها من يتغاضى عن كلام الأهل لأنهم حياتهم وحدهم.

جدول رقم (15) توزيع أفراد العينة حسب الأمور التي لا بد أن يعي بها المقبلين على الزواج من أجل تحقيق التوافق الزواجي

\begin{tabular}{|c|c|c|}
\hline$\%$ & العدد & الأمور التي لا بد أن يعي بها المقبلين على الزواج \\
\hline 18,4 & 45 & أن الزواج هدف وغاية \\
\hline 24,5 & 60 & الزواج رزق وايمان صادق وعلى الشاب أو الفتاة أن يؤمنا إيماناً صادقاً يقينيا بذلك \\
\hline 12,2 & 30 & الزواج ليس حقوقا متبادلة بين طرفين بقدر ما هو بناء مشترك بين طرفين \\
\hline 16,3 & 40 & الزواج مسؤوليات وتكاليف فالأحلام للزواج قبل الزواج قد لا يكون حقيقة بعد الزواج \\
\hline 28,6 & 70 & الزواج مشروع حقيقي لا بد فيه من الاستعداد لتحمل المسؤولية والصبر على ادائها \\
\hline 100 & 245 & 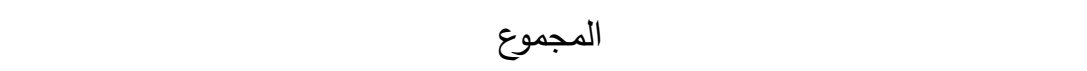 \\
\hline
\end{tabular}

يوضح الجدول السابق توزيع أفراد العينة حسب الأمور التي لا بد أن يعي بها المقبلين على الزواج من أجل تحقيق التوافق الزواجي ففي الترتيب الأول الزواج مشروع حقيقي لا بد فيه من الاستعداد لتحمل المسؤولية والصبر على ادائها بنسبة 28,6\% وفي الترتيب الثاني الزواج رزق وايمان صادق وعلى الثاب أو الفتاة أن يؤمنا إيماناً صادقاً يقينيا بذلك بنسبة 24,5\% وفي الترتيب الثالث أن الزواج هدف وغاية بنسبة 18,4\% وفي الترتيب الرابع الزواج مسؤوليات وتكاليف فالأحلام للزواج قبل الزواج قد لا يكون حقيقة بعد الزواج بنسبة 16,3\% وفي الترتيب الخامس الزواج ليس حقوقا متبادلة بين طرفين بقدر ما هو بناء مشترك بين طرفين بنسبة 12,2\% . 
نستتتج مما سبق أن هناك أمور يجب لا بد أن يعي بها المقبلين على الزواج من أجل تحقيق التوافق الزواجي أهمها أن الزواج مشروع حقيقي لا بد فيه من الاستعداد لتحمل المسؤولية والصبر على ادائها و الزواج رزق من جملة الأرزاق وعلى هذا على الثاب أو الفتاة أن يؤمنا إيماناً صادقاً يقينيا ان ما قسم لهما من الرزق سيأتيهما، وأن الزواج شعيرة من شعائر الله بقدر ما يعظمها الانسان في نفسه بقدر ما تسمو أهدافه وغاياته من هذه العبادة و الزواج بقدر ما هو سكن وارتياح ففيه مسؤوليات وتكاليف وتبعات للزواج قبل الزواج قد لا يكون حقيقة بعد الزواج و الزواج ليس حقوقا متبادلة بين طرفين بقدر ما هو بناء مشترك بين طرفين.

\section{استنتاجات وتوصيات البحث:}

أ- استنتاجات البحث: - n

1- غلبة نسبة الذكور على الاناث في مجتمع البحث حيث أن مقابلة الثباب المقبلين على الزواج كان الحديث معهم أسهل من الاناث المقبلين على الزواج أيضاً.

2- أن الغالبية العظمى من عينة الدراسة تقع في الفئة العمرية من 25-35 أي الفئة الثبابية.

3- يتضح اختلاف المستوى التعليمي للمبحوثين ففي المقدمة معهد مما يدل ذلك على قدرة عينة الدراسة على الاختيار الصحيح الذي يساعد على بناء أسرة جديدة ذات مبادئ وأسس.

4- اختلاف مهن الغالبية العظمى من عينة الدراسة فمنهم الموظف الحكومي وكاسب والأعمال الحرة ومن بدون عمل واخيراً الطلاب.

5- توزيع افراد العينة حسب أي مرحله عمريه تفضل الزواج فقي الترتيب الاول من 20-25سنه بنسبه 46,9\% وفي الترتيب الثاني من 25-30سنة بنسبة 40,8\% وفي الترتيب الثالث اقل من 20سنه بنسبه 12,2\% .

6- توزيع افراد العينة حسب كيفيه اختيار شريك الحياه ففي الترتيب الاول على اساس الحب للطرف الاخر (الاختيار العاطفي الحر) بنسبه 59,2\%. (20) 
مجلة لارك لذفلسدفة والذساذيات و الـعلوم الاجتماعية المجلد (2) العدد (41) السذة (2021) بحوث علم الاجتماع وعلم الذفس

7- توزيع أفراد العينة حسب تفضيل أسلوب التعامل من الطرف الآخر ففي الترتيب الأول أسلوب المودة والرحمة بنسبة

8- توزيع افراد العينة حسب دور الأسرة في اختيار فن شريك الحياه ففي الترتيب الاول دور كبير بنسبه 59,2\%.

9- توزيع افراد العينة حسب تفضيل اختيار الطرف الاخر ففي الترتيب الاول الحب قبل وبعد الزواج بنسبه 38,8\%.

10- توزيع افراد العينة حسب العوامل التي تؤثر على الاختيار الزوجي ففي الترتيب الاول المكانة الاجتماعية بنسبه 24,5\%.

11- أن الغالبية العظمى من عينة الدراسة لا تؤيد فكرة الزواج عن طريق الوسائل الحديثة يليها من يوافق بذلك ثم من يوافق الى

حد ما.

12- أن التسرع في الاختيار الزواجي يؤدي الى مشاكل زوجية قد تؤدي الى الطلاق وهذا ما أكدته الغالبية العظمى من عينة

الدراسة.

13- توزيع افراد العينة حسب التصرف عند اعتراض الاهل على اختيار الثريك لأنه غير مناسب ففي الترتيب الاول أتغاضى عن كلام الاصدقاء والقرار قراري وحدي وانا الذي سوف يعيش معه.

14- توزيع أفراد العينة حسب الأمور التي لا بد أن يعي بها المقبلين على الزواج من أجل تحقيق التوافق الزواجي ففي الترتيب الأول الزواج مشروع حقيقي لا بد فيه من الاستعداد لتحمل المسؤولية والصبر على ادائها.

\section{ب- توصيات الاراسة}

1- التركيز في المناهج التعليمية على الأسرة وتكوينها وأهميتها والأسباب التي تساعد على تكوين أسرة ناجحة. 2- إصدار كتيبات علمية ونشرات تتناول الزواج ومعايير الاختيار للزواج وتتناول الآثار المترتبة على سوء الاختيار. 3- - توعية الأسرة بعدم إرغام الأبناء على اختيار شريك حياة لا يرغب في الزواج منه والاكتفاء بالنصح والمشورة. 4- عدم رد الأكفاء إذا توفرت فيهم مقومات الاختيار الزواجي الصحيح من مقومات دينية واخلاقية وبننية. 
مجلة لارك لذفلسدفة والذساذيات و الـعلوم الاجتماعية المجلد (2) العدد (41) السذة (2021) بحوث علم الاجتماع وعلم الذفس

5- توعية الثباب عن طريق وسائل الإعلام المقروهة والمسموعة والمرئية بأهمية الزواج وأهمية قرار الاختيار والتوعية بأسس الاختيار المناسبة وذلك للمحافظة على كيان المجتمع.

6- تحقيق قدر كبير من الوقاية والمعالجة للمشكلات الأسرية وذلك بالحرص على تقديم الاعلام الواعي والمفيد والذي يمكن ان يخدم الأسرة فيصبح هناك برامج وإصدارات للتوعية بأسس بناء البيت وغيرها لحل المشكلات الأسرية وفق الأسس والطرق الصحيحة وأخرى لطرق وأساليب التربية والتوجيه.

7- الاهتمام بوضع سياسية للتوعية الأسرة وتغيير مفاهيم أولياء الأمور حول أسس الاختيار الزواجي والاتجاه نحو تدعيم فكرة التكافؤ الزواجي. 8- إقامة دورات تأهيلية وتثقيفية للزوجين قبل الزواج. مصادر البحث:

1- Ibrahim Abdel-Hadi El-Meligy, Community Organization, theoretical approaches and a realistic vision, Modern University Office, Alexandria.

2- Ahmad Zaki Badawi, The Dictionary of Social Sciences Terms, 3rd Edition, Beirut, Lebanon Library, 1993.

3- Ahmed Shafiq Al-Sukkari, Dictionary of Social Work, University Knowledge House, Alexandria, 2000.

4-Ahmed Mustafa Khater, Method of Organizing Society, Modern University Office, Alexandria, 1984.

5- Ahmed Hussein Al-Laqani, Ali Al-Jamal, The Dictionary of Educational Terms Knowledge in Curricula and Teaching Methods, The World of Books, Cairo, 1996.

6- Anthony Giddens, Family Sociology, Center for Arab Unity Studies, Beirut, 2005.

7-Hussein Abdel-Hamid Rashwan, Family and Society, Study in Family Sociology, University Youth Foundation, 2003. 
مجلة لارك لذفلسدفة والذساذيات و الـعلوم الاجتماعية المجلد (2) العدد (41) السذة (2021) بحوث علم الاجتماع وعلم الذفس

8-Kholoud Bint Muhammad Ali Yusef Sahaf, Marital Compatibility and its Relation to Family

Stability for a Sample of Married Persons in the City of Makkah Al-Mukarramah, Master Thesis,

Umm Al-Qura University, Saudi Arabia, 2016.

9- Dalal Al-Alami and Atallah Al-Khalidi, Marital Family Counseling, Sana'a House for

Publishing and Distribution, Amman, 2009.

10-Zayed Muhammad Jaber and others, Islam and combating violence against women, National

Council for Women Library, Cairo, 2006.

Samia Al-Saati, Choice for Marriage and Social Change, 3rd Edition, Cairo, 2002.

11-Samiha Karam Tawfiq, Introduction to Family Relationships, The Anglo-Egyptian Library,

Cairo, 1996.

12- Sana Ahmed Amin, Marriage between Success, Crisis and Failure, Arab Thought House for

Printing and Publishing, 2008.

13-Sanaa El-Khouly, Marriage and the Family in a Changing World, House of Knowledge

University, Alexandria, 1988.

14-Mr. Abdel Ati and Others, Family and Society, University Knowledge House, 2006.

15-Salih Muhammad Abu Jadu, The Psychology of Social Upbringing, Al Masirah House Jordan, 2010 .

16-Abdul Khaleq Muhammad Afifi, Building the Family and Contemporary Family Problems, Modern University Office, 2011. 
مجلة لارك لذفلسدفة والذساذيات و الـعلوم الاجتماعية المجلد (2) العدد (41) السذة (2021) بحوث علم الاجتماع وعلم الذفس

17-Abdel Raouf El-Dabaa, Family Sociology, The Arab Family in a Changing World, The International House for Publishing and Distribution, Cairo, 2008.

18- Adly Al-Samri and others, Sociology of the Family, Dar Al-Masirah, Amman - Jordan, 2014.

19-Essam Nimer and others, Children, Family and Society, Dar Al-Fikr for Publishing and Distribution, Jordan, 1989.

20-Alaa El-Din Al-Kafafi, Family Counseling, University Knowledge House, Cairo, 2006.

21-Alia Shukry, Contemporary Trends in the Study of the Family, University Knowledge House, Alexandria, 1988.

22-Faten Al-Sharif, Family and Kinship, Study in Social Anthropology, Dar Al-Wafaa for the World of Printing and Publishing, Alexandria, 2005.

23-Faisal Mahmoud Gharabia, Social Work with Family and Children, 2nd Edition, Wael Publishing and Distribution House, Amman - Jordan, 2012.

24-Muhammad Al-Mahdi, The Art of Marital Happiness, The Anglo-Egyptian Library, Cairo, 2007.

25-Muhammad Atef Ghaith, Sociology of Systems, Change and Problems, Part 2, Dar Al Ma'arif, Alexandria, 1987.

26- Muhammad Atef Ghaith, Dictionary of Sociology, University Knowledge House, 2006. 
مجلة لاررك لذفلسفة واللسدانيات و العدوم الاجتماعية المجلد (2) العدد (41) السذة (2021) بحوث علم الاجتماع وعلم الذفس

27- Muhammad Abdo Mahjoub, Anthropology of Marriage, Family and Kinship, University

Knowledge House, Alexandria, 1984.

28-Muhammad Uqla, The Family System in Islam, The Modern Message Library, Jordan, Amman, 2nd Edition, 1989.

29- Muhammad Yusri Ibrahim Daabs, The Family in the Religious and Social Heritage, Dar Al Ma'arif, 1995.

30-A Handbook of Sociology pout hedge kengapanl (itd) fifth Edition, 1994.

31-Ahmed Zaki Badaoui, Dicitionary of the the Society sciences. French; Arabic. Librairie du Liban Sequare, Beirut Liban; 1993.

32-Harville, Getting the love you want first books by Henry Hoit and company.newyork, 1988.

33-R. Hill \&Hanson : Marriage and Family Living N.Y. 1980. 